\title{
Social Pediatrics: Satya Gupta and A P Dubey (eds)
}

\author{
Published by Paras Medical Publisher, India, ISBN: 978-81-8191-345-6, \\ First Edition: 2011
}

\author{
Bhavneet Bharti
}

Received: 27 May 2011 / Accepted: 27 May 2011 /Published online: 11 June 2011

(C) Dr. K C Chaudhuri Foundation 2011

Social pediatrics has been one of the few subspecialties that bind children and parents with their treating pediatricians together. An apt understanding between children, parents, and various types of healthcare providers is an urgently needed common denominator at a time when myriad of childhood and adolescent issues are rapidly emerging in the modern sociocultural landscape. Conventionally, pediatricians are focused on the medical model of child health care, focusing on clinical problems and their management. The crucial issues of child advocacy, gender bias and adolescent needs, invariably, take a back seat both during their training and practice. In this regard, this book by Gupta and Dubey, indeed, expands the limited spectrum of literature on social pediatrics in the Indian setting. The book, spread over thirty-three chapters, vividly captures some of the important topics in Social Pediatrics like poverty, nutrition, injuries, adoption, child abuse, juveniles in conflict with law and health-related challenges faced by children in marginalized settings of urban slums as well as tribal areas.

Various determinants of child morbidity and mortality have been comprehensively discussed by worthy authors. Yet, an exclusive chapter on Millennium Development Goals and Integrated Management of Neonatal and childhood illnesses would have been useful for the young pediatricians. The chapter on growth and development elaborates only the IAP growth curves, completely ignoring the WHO Multicentric growth charts (2006) proposed by WHO. The WHO growth charts have been used during the major demographic surveys of our country (National Family Health surveys-3) to permit international comparisons. The Govt. of India too has recommended the use of WHO charts in the Anganwadis under the ICDS all over India. A critique on the use of various growth charts would have given an insight into strengths and limitations on the use of various charts.

The chapter on school health could have been enhanced by including major initiatives taken by Govt. of India to provide cooked mid day meals to all primary school children. The laudable effort of CBSE in initiating the Adolescent education programme, bringing out of various school health manuals and launching a separate physical and health education syllabus also merrits mention. The book, no doubt, offers vast amount of useful information for an examination candidate but falls short of evaluating some of issues critically.

Some of the chapters lack any cross references and no uniform pattern for bibliography has been followed. For these reasons it is hoped that the future reprints shall be better organized and carefully proof read to remove the existing typographical and format errors. Yet, this book with wide ranging topics of social relevance in pediatrics may be just the thing that pediatricians need right now. Moreover, the book is competitively priced and is quite the right size. Certainly, the book is recommended for postgraduate pediatric residents aspiring to obtain the basic knowledge in the field of social pediatrics.

B. Bharti $(\bowtie)$

Advanced Pediatric Center, PGIMER,

Chandigarh, India

e-mail: bhavneetb@yahoo.com 